\title{
The Med proteins of yeast and their function through the RNA polymerase II carboxy-terminal domain
}

\author{
Lawrence C. Myers, ${ }^{1,3}$ Claes M. Gustafsson, ${ }^{1,3}$ David A. Bushnell, ${ }^{1}$ Mary Lui, ${ }^{2}$ \\ Hediye Erdjument-Bromage, ${ }^{2}$ Paul Tempst, ${ }^{2}$ and Roger D. Komberg ${ }^{1,4}$ \\ ${ }^{1}$ Department of Structural Biology, Stanford University School of Medicine, Stanford, California 94305-5400 USA; \\ ${ }^{2} \mathrm{M}$ olecular Biology Program, M emorial Sloan-Kettering Cancer Center, N ew York, N ew York 10021 USA
}

\begin{abstract}
Mediator was resolved from yeast as a multiprotein complex on the basis of its requirement for transcriptional activation in a fully defined system. Three groups of mediator polypeptides could be distinguished: the products of five SRB genes, identified as suppressors of carboxy-terminal domain (CTD)-truncation mutants; products of four genes identified as global repressors; and six members of a new protein family, termed Med, thought to be primarily responsible for transcriptional activation. Notably absent from the purified mediator were Srbs 8, 9, 10, and 11, as well as members of the SWI/SNF complex. The CTD was required for function of mediator in vitro, in keeping with previous indications of involvement of the CTD in transcriptional activation in vivo. Evidence for human homologs of several mediator proteins, including Med7, points to similar mechanisms in higher cells.
\end{abstract}

[Key Words: RNA polymerase II holoenzyme; transcription; CTD; Saccharomyces cerevisiae]

Received August 26, 1997; revised version accepted October 27, 1997.

Mediator was discovered as an activity in a crude fraction that relieved activator inhibition of transcription (squelching) in yeast nuclear extract (Kelleher et al. 1990). The same crude fraction was subsequently shown to be required for enhancement of transcription in a partially fractionated yeast system (Flanagan et al. 1991). Other, initially unrelated studies identified SRB genes from a screen for RN A polymerase II carboxy-terminal domain (CTD)-interacting proteins and showed the association of these proteins with the polymerase in a large complex (Koleske and Young 1994). These two lines of work converged with the resolution of mediator to homogeneity as a complex of $\sim 20$ proteins, including several SRB gene products (Kim et al. 1994). The only discordant finding was that Srb proteins were present at a level $\sim 6 \%$ that of RNA polymerase subunits in yeast extracts, whereas about half the RNA polymerase purified from the extracts was associated with mediator. This apparent conflict was resolved by evidence for the recycling of mediator to initiation complexes and the absence of mediator from el ongating pol ymerases, which constitute the majority of the enzyme in a cell (Svejstrup et al. 1997).

Purified mediator was found to possess three functional activities (Kim et al. 1994): It stimulated basal

\footnotetext{
${ }^{3}$ These authors contributed equally to this work.

${ }^{4}$ Corresponding author.

E-MAIL komberg@stanford.edu; FAX (415) 723-8464.
}

transcription in a system reconstituted from essentially homogeneous yeast proteins $\sim 10$-fold; it enabled a response of the reconstituted system to activator proteins by as much as 30-fold, for an overall effect on transcription as great as 300-fold; and it stimulated phosphorylation of the CTD by TFIIH kinase by 30 - to 50-fold. Major objectives of further work have been to identify the components of mediator responsible for these activities, to determine the mechanisms, and to establish the relevance for transcriptional regulation in vivo. To this end, characterization with antisera against various yeast proteins enabled the provisional identification of Gal11, Sug1, Srb2, Srb4, Srb5, and Srb6 among the set of mediator polypeptides (Kim et al. 1994). Subsequent peptide sequence analysis confirmed the presence of Gal 11 and identified three further mediator polypeptides as products of the previously described SIN4, RGR1, and ROX3 genes (Li et al. 1995; Gustafsson et al. 1997). The significance of this work was several fold: It united the Gal 11, Sin4, and Rgr1 proteins, products of disparate genetic screens, in a common biochemical entity; it revealed the occurrence in mediator of proteins implicated by genetic studies in transcriptional repression in vivo, thus showing a role for mediator in negative, as well as positive, regulation of transcription; and it pointed to a modular organization of the mediator, with Gal11, Sin4, Rgr1, and a 50-kD polypeptide forming a separable subassembly of the larger complex. This work, however, did not address the questions of physiologic relevance or mecha- 
nism. It remained to make any connection between functions in vitro and phenotypes in vivo.

Here, we present a nearly complete molecular description of mediator. In addition to the products of known genes, we identify a novel family of mediator polypeptides required for transcriptional activation. We provide direct evidence for mediator function through the CTD in vitro, in keeping with the phenotypes of CTD truncation mutants in vivo. The occurrence of human homologs of a number of mediator proteins points to the possible existence of a corresponding mechanism in higher cells.

\section{Results}

Isolation of free mediator complex

In past work, mediator was isolated either as a complex with 12-subunit core RNA polymerase II, or following displacement from this holoenzyme complex by antiCTD antibodies (Kim et al. 1994). For the isolation of mediator for peptide sequence analysis, we turned to commercial yeast (Fleischmann's), and noticed the resolution of mediator polypeptides in two peaks in the fourth step of the fractionation procedure, chromatography on M ono Q. The first peak was devoid of polymerase subunits and apparently represented free mediator, whereas the second peak contained the previously described hol oenzyme (Fig. 1).

The free mediator was further purified by chromatography on TSK-Heparin-5-PW and Mono S, followed by gel filtration through Bio-Sil SEC 400. Peak fractions from gel filtration were pooled and analyzed by SDSPAGE and Coomassie Blue staining (Fig. 2). As many as 18 polypeptides were resolved in the molecular weight range 14-130 kD, 16 of which are described here. In addition to the products of known genes, there were seven products of novel genes, which we have termed MED, for mediator. Densitometry of the SDS-gel indicated that all mediator polypeptides were present in roughly equal amounts, except for Srb5, at $\sim 40 \%$ of the level of the other proteins, members of the Gal 11 module (Gal11, Sin4, Rgr1, and p50, here termed M ed3), at variable levels between $50 \%$ and $75 \%$, and Med 2 at 30\% (Fig. 2).

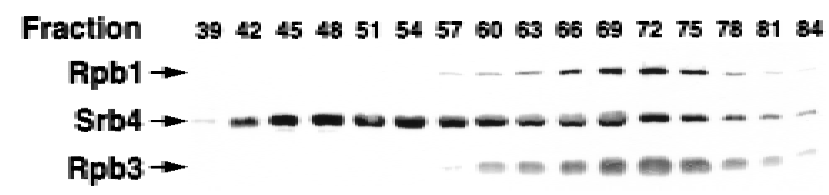

Figure 1. Separation of free mediator and RN A polymerase II holoenzyme by chromatography on Mono Q. Hydroxyapatite fractions containing both mediator and polymerase II were applied to M ono $\mathrm{Q}$ and eluted with a linear gradient of potassium acetate. Fractions were analyzed by immunobl otting with antibodies against the mediator subunit Srb4 and against the polymerase II subunits Rpb1 and Rpb3. Mediator, in the free form, peaked at $600 \mathrm{~mm}$ potassium acetate and, in the holoenzyme form, peaked at $800 \mathrm{~mm}$.

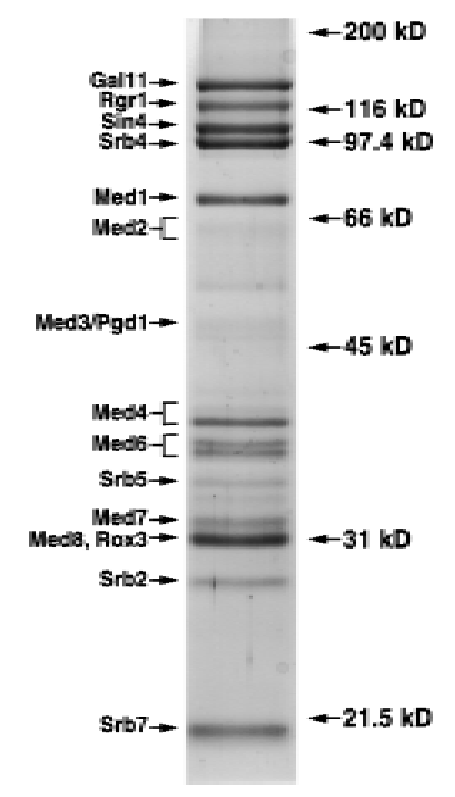

Figure 2. Polypeptide composition of free mediator. Peak fractions from Bio-Sil SEC 400 were pooled and analyzed by SDSPAGE in an $11 \%$ gel. Proteins were revealed by staining with Coomassie blue. Srb6 was present, but was too small to be detected in the gel system used. Positions of molecular mass markers are indicated on the right.

The amount of M ed2 may be underestimated, because it formed a diffuse band in the gel. Functional assays of the homogeneous free mediator showed all the activities found previously for the protein derived from RN A polymerase holoenzyme: The free mediator stimulated basal transcription in a fully reconstituted system 20.5-fold, enabled a further increase in transcription in the presence of Gal4-VP16 activator protein of 18.4-fold (Fig. $3 A$ ), and stimulated phosphorylation of the CTD by TFIIH as much as 40-fold (Fig. 3B).

\section{Identification of five new mediator subunits}

A highly purified mediator fraction was resolved by SDSPAGE, transferred to a polyvinylidene difluoride (PVDF)membrane, and stained with Ponceau S. Bands denoted M ed2, M ed3, M ed4, M ed5, M ed7, and M ed8 (see Fig. 2) were excised and digested with trypsin, and the resulting peptides were fractionated by reverse-phase high-pressure liquid chromatography (HPLC) and sequenced. Perfect matches were found to sequences in the Saccharomyces cerevisiae genome database (Table 1 ), and the masses of peptides determined by mass spectrometry were in good agreement with the theoretical masses of the expected tryptic peptides for the individual gene products.

Med4 and M ed5 yielded peptide sequences from the same uncharacterized open reading frame, and thus derived from a single protein migrating as a doublet, hereafter referred to as M ed4. The final member of the Gal11 module, the p50/M ed3 protein, proved to be the product 
A

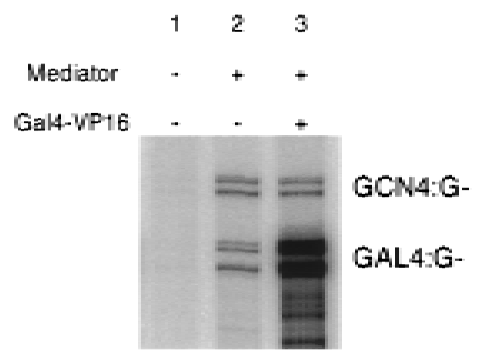

B

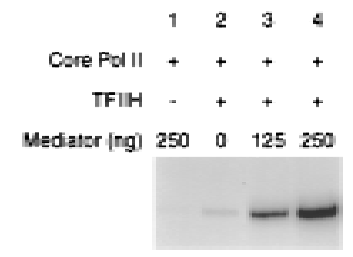

Figure 3. Functional characterization of free mediator. (A) Activities of pure mediator (heparin fraction) in transcription. The final gel filtration fraction used to assess the stoichiometry of mediator polypeptides (see text) was functional ly indistinguishable from the heparin fraction used here and of comparable purity (data not shown). Transcription was performed with templates containing binding sites for Gal4 (GAL4:G $\rightarrow$ ) and $\mathrm{Gcn} 4$ (GCN 4:G $\rightarrow$ ) upstream of the S. cerevisiae CYC1 promoter fused to a G-less cassette (Kim et al. 1994). Reaction mixtures contained $2 \mu \mathrm{g}$ of RN A polymerase II, $0.5 \mu \mathrm{g}$ of mediator (Ianes 2,3 ), and $10 \mathrm{ng}$ of Gal4-VP16 (lane 3), in addition to basal transcription factors as described (Kim et al. 1994). Enhancement of basal transcription (lane 2 ) was 20.5-fold and could vary between 5and 60 -fold depending on reaction conditions. Activation of transcription by Gal4-VP16 (lane 3) was 18.4-fold, and could vary between 10- and 20-fold depending on reaction conditions. (B) Free mediator stimulates CTD phosphorylation by TFIIH. RN A polymerase II (Core Pol II, 100 ng) was phosphorylated by holoTFIIH $(20 \mathrm{ng})$ in the presence of increasing amounts of a free mediator (heparin fraction). Stimulation of CTD kinase activity was 17.3-fold (lane 3) and 36.3-fold (lane 4).

of the previously identified PGD1 (HRS1) gene (Bröhl et al. 1994). Med7 derived from an uncharacterized open reading frame. The $M$ ed 8 band gave rise to peptide sequences from two open reading frames, one corresponding to the previously identified holoenzyme component Rox3 (Gustafsson et al. 1997), and a second, equally abundant protein, from an open reading frame partially characterized in the yeast chromosome II sequencing effort (Démolis et al. 1993), for which we retain the designation Med8.

Although none of the MED sequences show enzymatic motifs or other strong homologies clearly rel ated to mediator function in transcription, there are some features of note in the newly defined sequences. The existence of a putative leucine zipper motif in MED8 at amino acids 69-90 has been recognized previously (Démolis et al. 1993). MED2 contains an asparaginerich region at the carboxy terminus of $>100$ amino acids. A polygl utamine stretch, common to many transcription proteins, including Gal 11, has been noted in Pgd1(Hrs1) (Santos-Rosa et al. 1996). A long with other members of the Gall1 mod- ule, Pgd1(Hrs1) is basic, whereas M ed7 and Rox3 are neutral, and the rest of the mediator subunits are acidic (Table 1).

Med2, Med4, Med7, and Med8 were expressed in re combinant form, and polyclonal antibodies were obtained. The association of these proteins with RN A polymerase II holoenzyme was shown by copurification and coimmunoprecipitation. RNA polymerase II holoenzyme was purified from strain BJ926 by chromatography on Bio-Rex 70, DEAE-Sephacel, hydroxyapatite, Mono $\mathrm{Q}$, and Bio-Sil SEC 400. Immunoblot analysis showed coelution from hydroxyapatite and Bio-Sil SEC 400 of M ed2, Pgd1(Hrs1), M ed4, M ed7, M ed8, the polymerase subunits Rpb1 and Rpb3, and Srb4 (Fig. 4).

Immunoprecipitation was performed with anti-M ed2 antibodies coupled to protein A-Sepharose. Holopolymerase was incubated with the antibody-Sepharose, followed by washing under stringent conditions. Immunoblot analyses revealed that Med2, Pgd1(Hrs1), Med4, M ed7, M ed8, Rpb3, and Srb4 were al most entirely bound by the antibody-Sepharose (Fig. 5A). Immunoprecipitation with anti-M ed4 antibodies gave the same result (Fig. 5B). We conclude that Med2, Pgd1(Hrs1), M ed4, Med7, and Med8 in the holopolymerase preparation were entirely associated with the hol oenzyme.

\section{MED gene requirement for cell viability}

Y east strains were constructed in which each of the previously uncharacterized open reading frames encoding $M$ ed proteins was deleted. Following sporulation and tetrad dissection, viability segregated 2:2 for the med4, med7, and med8 deletions. Tetrad dissection of the med2 deletion strain yielded four viable spores, but the two spores containing the disrupted gene were significantly smaller and unable to grow on galactose as the sole carbon source (data not shown).

\section{Mediator binds directly to a CTD peptide}

A GST fusion protein that included all 26 repeats of the yeast CTD and 40 amino acids of linker sequence was loaded on glutathione-Sepharose. Pure mediator was completely bound by the resulting GST -CTD Sepharose, whereas none was bound by a GST-Sepharose control (Fig. 6). What little mediator was not bound by the GSTCTD Sepharose could most likely be attributed to a small amount of GST-CTD that bled off the column. Approximately half of the bound mediator was eluted with gl utathione, which al so displaced a majority of the GST-CTD. The remaining mediator and GST-CTD were eluted under denaturing conditions. There was no mediator in eluates from the GST-Sepharose control.

\section{CTD required for mediator function in vitro}

RNA polymerase II lacking a CTD (Pol II $\triangle$ CTD) was prepared by proteolysis as described (Li and Kornberg 1994). Pol II $\Delta$ CTD was indistinguishable from wild-type enzyme in a basal transcription reaction (Fig. 7). Media- 
Myers et al.

Table 1. Mediator subunits

\begin{tabular}{|c|c|c|c|c|c|c|}
\hline Gene & $\begin{array}{l}\text { Deletion } \\
\text { phenotype }\end{array}$ & $\begin{array}{l}\text { Human } \\
\text { homolog }\end{array}$ & $\begin{array}{l}\text { Protein } \\
\text { mass (kD) }\end{array}$ & $\begin{array}{l}\text { A pparent } \\
\text { mass }(k D)^{a}\end{array}$ & $\mathrm{pl}$ & Reference $^{b}$ (yeast ORF) \\
\hline GAL11 & conditional & & 120 & 130 & 10.0 & (1) \\
\hline RGR1 & inviable & + & 123 & 115 & 9.0 & (1) \\
\hline SIN4 & conditional & & 111 & 100 & 8.8 & (1) \\
\hline SRB4 & inviable & & 78 & 98 & 5.1 & (2) \\
\hline MED1 & conditional & & 64 & 70 & 4.7 & (3) \\
\hline MED 2 & conditional & & 48 & 62 & 4.4 & this study (YDL005c) \\
\hline PGD $1^{c}$ & conditional & & 47 & 48 & 9.4 & this study \\
\hline MED 4 & inviable & & 32 & $38^{d}$ & 4.5 & this study (YOR174w) \\
\hline MED6 & inviable & + & 32 & $36^{d}$ & 5.2 & (4) \\
\hline SRB5 & conditional & & 34 & 35 & 4.7 & $(2)$ \\
\hline MED 7 & inviable & + & 32 & 31 & 6.7 & this study (YOL135c) \\
\hline MED 8 & inviable & & 25 & 30 & 5.3 & this study (YBR193C) \\
\hline ROX3 & inviable & & 25 & 30 & 6.6 & (5) \\
\hline SRB2 & conditional & & 23 & 27 & 5.2 & (2) \\
\hline SRB7 & inviable & + & 16 & 19 & 4.8 & (6) \\
\hline SRB6 & inviable & & 14 & 15 & 4.6 & (2) \\
\hline
\end{tabular}

Boldface type indicates the five new mediator subunits reported in this paper.

${ }^{a}$ As judged by SDS-PAGE analysis with respect to molecular weight standards.

b(1) Li et al. (1995); (2) Thompson et al. (1993); (3) Bjorklund et al. (unpubl.); (4) Lee et al. (1997); (5) Gustafsson et al. (1997); (6) Hengartner et al. (1995).

'This gene is also known as HRS1.

$\mathrm{d} M$ ed 4 and M ed6 are often observed as doublets.

tor, however, failed to stimulate basal transcription by Pol II $\triangle$ CTD, nor did it elicit a response of Pol II $\triangle$ CTD to Gal4-VP16 or GCN 4, in marked contrast to its effect on the wild-type polymerase (Fig. 3A; Kim et al. 1994).

\section{Human homolog of yeast Med7}

A cDNA encoding a human homolog of the Med7 protein (hM ed7) was identified in a search of the NCBI database of expressed sequence tags (Fig. 8A). The regi on of homol ogy between the deduced amino acid sequences of the two proteins encompasses almost all of the yeast protein and 211 of 235 residues of the human protein (Fig. 8B). The sequences exhibited $31.8 \%$ identity and $59.2 \%$ similarity in this extended region, essentially the same as the degree of homology between yeast and human general transcription factors, and between yeast and human Med6 (Lee et al . 1997) and Srb7 (Chao et al. 1996). Full-length hM ed7 failed to complement deletion of the yeast homolog (data not shown), as al so found for M ed6 and Srb7.

\section{Discussion}

Fractionation of RNA polymerase II transcription systems has reveal ed two multi protein complexes that confer responsiveness to activators, the TAF (TATA binding protein-associated factor) compl ex (Pugh and Tjian 1990; Burley and Roeder 1996) and mediator (Kelleher et al. 1990; Kim et al. 1994). Subsequent studies were directed

A

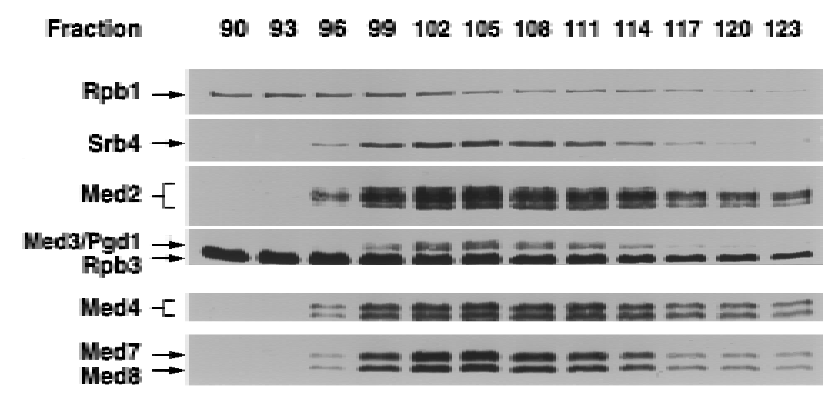

B

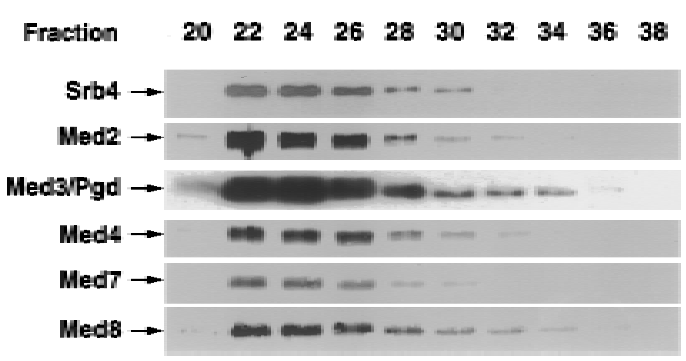

Figure 4. Med proteins comigrate during hydroxyapatite chromatography and gel filtration. (A) The peak of RNA polymerase II holopolymerase from DEAE-Sephacel was applied to a $20 \mathrm{ml}$ hydroxyapatite col umn and el uted with a $200 \mathrm{ml}$ gradient of $0.01-0.2 \mathrm{~mm}$ potassium phosphate. Fractions were analyzed by SDS-PAGE in a 10\% gel and immunoblotted with antibodies directed against the proteins indicated. (B) The mediator peak from Mono Q was subjected to gel filtration through Bio-Sil SEC 400. Fractions were analyzed by SDS-PAGE in a $10 \%$ gel and immunoblotted with antibodies directed against the proteins indicated. 
A

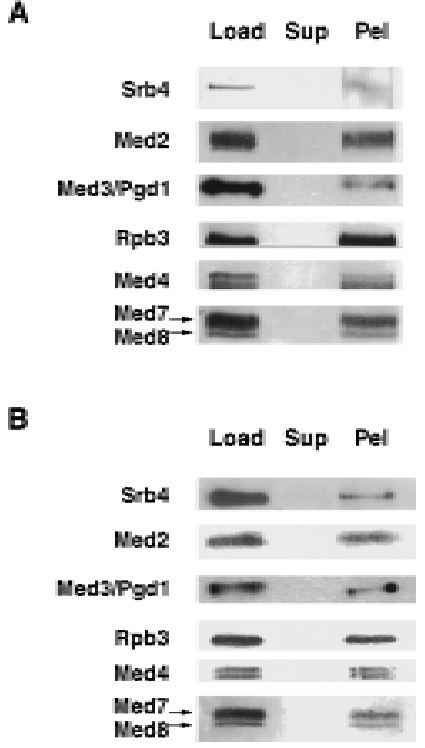

Figure 5. Co-immunoprecipitation of M ed proteins with RNA polymerase II holoenzyme. (A) Immunoprecipitation by antiMed2 antibody coupled to protein A-Sepharose. An RNA polymerase II holopolymerase fraction from Mono Q (Load, $5 \mu \mathrm{g}$ ) was incubated with anti-M ed2 antibody beads. The supernatant (Sup) was removed, the beads were washed, and immunoprecipitated protein was eluted (Pel). Equal amounts of the load, supernatant, and eluted proteins were analyzed by immunoblotting with antibodies against the proteins indicated. (B) Immunoprecipitation with anti-M ed4 antibody coupled to protein A-Sepharose, as in A.

toward the molecular characterization of these complexes, as a prelude to genetic and mechanistic analysis. A major goal has been to test the rel evance of transcriptional activation supported by the complexes in vitro to gene regulation in vivo. Eight RNA polymerase II TAFs were identified, and genes for five of the proteins were mutated in yeast. These mutations had few effects on

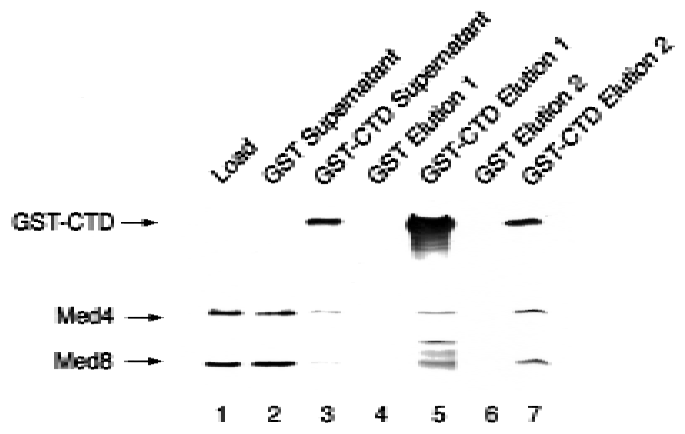

Figure 6. Mediator binds directly to the CTD. Free mediator was applied to GST-CTD and GST (control) resins and eluted with glutathione (Elution 1) and SDS (Elution 2). Proteins were analyzed by immunoblotting with antibodies directed against Med4, Med8, and the CTD (to reveal the presence of GSTCTD).

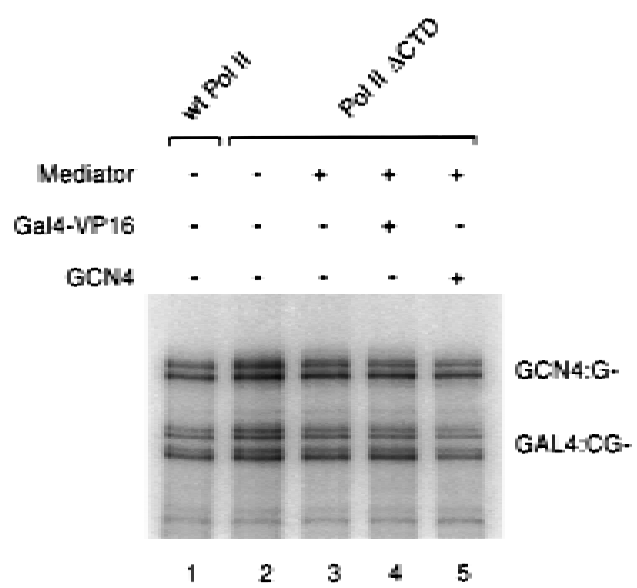

Figure 7. CTD requirement for mediator function in vitro. Transcription was performed as described with wild type polymerase $(1 \mu \mathrm{g})$ or Pol II $\triangle$ CTD $(1 \mu \mathrm{g})$ in the presence of mediator (500 ng), Gal 4-VP16 (10 ng), and GCN 4 (10 ng) as indicated.

transcription, pointing to a role for TAFs at only a smal I number of yeast promoters (Moqtaderi et al. 1996; Walker et al. 1996).

In contrast, mediator appears to play a more general role. The five new mediator genes reported here bring to sixteen the number so far identified, with the possibility of another two remaining. Three groups of mediator genes may be distinguished: a subset of the SRB genes, which were originally isolated from a genetic screen for CTD-interacting proteins, and whose products may be involved in CTD binding; GAL11 and related members, whose roles in vivo extend to transcriptional repression; and the MED genes, analyzed here. A temperature-sensitive mutation in the SRB4 gene was shown to abolish transcription from all promoters tested at the restrictive temperature, indicating a general requirement of mediator for transcription (Thompson and Young 1995). The consequences of MED gene mutation establish a role in transcriptional activation. A med6 ${ }^{\text {ts }}$ strain (Lee et al. 1997) is defective in GAL gene induction in vivo, and the isolated med6 ${ }^{\text {ts }}$ holoenzyme exhibits no response to transcriptional activators in vitro.

The correlation between genetic and biochemical studies of transcription control is extended by evidence for a CTD requirement. Transcription from some promoters is reduced by CTD truncation in vivo (Scafe et al. 1990) and in nuclear extracts (Liao et al. 1991). Here we report that the response to activator proteins in the presence of mediator is abolished by removal of the CTD from RN A polymerase II in a pure transcription system. Consistent with these findings, proteins from yeast whole cell extract including Srb proteins are retained by CTD polypeptide immobilized on a solid support (Thompson et al. 1993), and we show that pure mediator, reduced to a minimal set of polypeptides required for function in vitro, and devoid of other proteins, is bound by such a CTD column as well.

An important difference between the mediator de- 
A

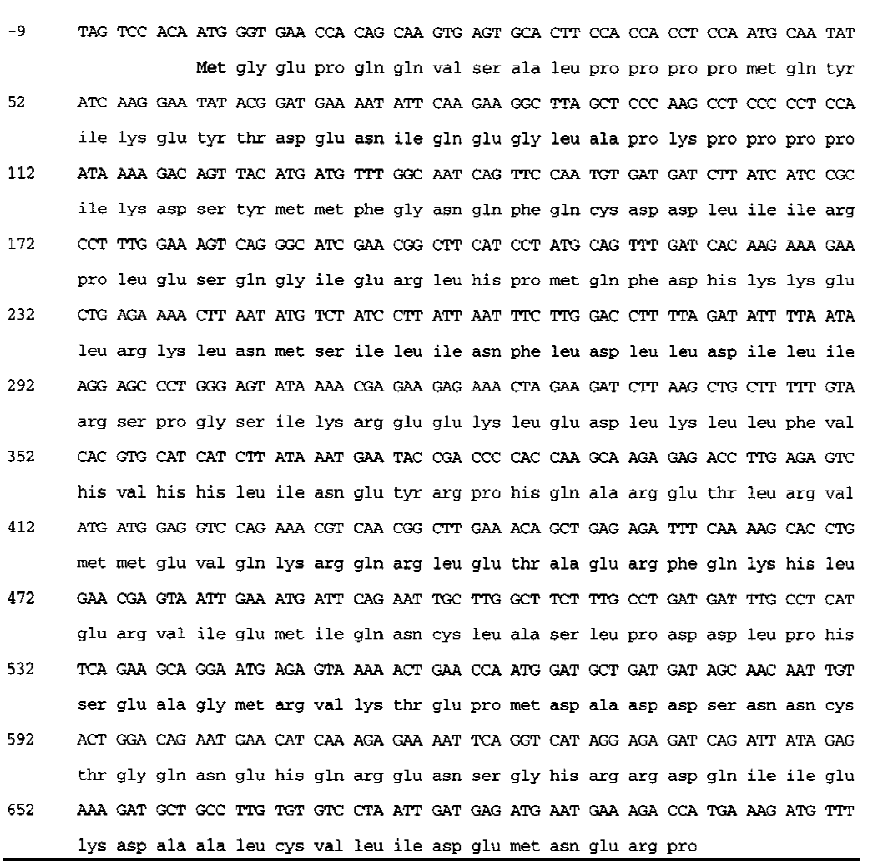

hMED7

Figure 8. Human homolog of yeast Med7 protein. (A) Human Med7 homolog sequence (GenBank accession no. AF031383). (B) Human and yeast Med7 alignment. Colons indicate identity and dots similarity by the program FASTA (Pearson and Lipman 1988). FASTA aligned the sequences using the BLOSU M 50 matrix resulting in a Smith-Waterman score of 291 , and a $31.8 \%$ identity and $59.2 \%$ similarity in a 211 -amino-acid region of overlap.

scribed here and that reported previously (Kim et al. 1994) is our isolation of the complex in a free form, not associated with RNA polymerase II in a holoenzyme. The relative abundance of free and polymerase-bound mediator was somewhat variable from one preparation to another, possibly dependent, in part, on the yeast strain used. The occurrence of free mediator is in keeping with the mediator cycle proposed elsewhere (Svejstrup et al. 1997). Isolation as a free, stoichiometric species underlines the integrity of the complex, further distinguishing it from a collection of proteins interacting independently with the polymerase CTD.

Proteins absent from the mediator isolated here are also noteworthy. In particular, TFIIF was separated from the mediator during fractionation, as noted elsewhere (Svejstrup et al. 1997), and Sug1, Srb8, Srb9, Srb10, and Srbll and SWI/SNF proteins were undetectable. Whereas interactions with these proteins are not ruled out, a key finding reported here is a lack of requirement for any additional proteins for support of transcriptional activation, for stimulation of basal transcription, or for stimulation of CTD phosphorylation. In particular, Srb10 and Srb11 are not required for any of these functions. The only caveat is that trace amounts of additional proteins might play catalytic roles, and reconstitution of mediator from recombinant proteins is required for this possibility to be excluded.

Whereas most mediator polypeptides identified here are roughly equimolar, some occur in lesser amounts, such as Gal11, Sin4, Rgr1, and M ed3. The similar behavior of these four proteins is in keeping with three additional lines of evidence. First, the four proteins are basic, in contrast with the neutral or acidic nature of all other mediator polypeptides (T able 1). Second, Rgr 1 truncation causes the loss of Gal11, Sin4, and p50/M ed3 from mediator (Li et al. 1995). Third, mutations in Gal 11, Sin4, and Rgrl confer similar phenotypes (Jiang and Stillman 1995; Jiang et al. 1995). We now identify p50/M ed3 as the product of the PGD1(HRS1) gene. Others have noted that $\mathrm{Hrs} 1$ mutations have similar consequences to those of Gal11, Sin4, and Rgrl deficiencies and have suggested its identification with p50/Med3 (Piruat et al. 1997). HRS1 was found in a genetic screen for mutations that could suppress a hyper-recombinant phenotype of hprls cells (Santos-Rosa et al. 1995). Other suppressors of this phenotype include genes encoding Srb2 (Piruat and Aguilera 1996), Rpb2, and TFIIB (Fan et al. 1996). The deletion of HRSI was shown to greatly reduce the frequency at which sequences between direct repeats are deleted (Santos-Rosa et al. 1996). This result was obtained not only for hpr1s cells, but also for wild-type and Rad52 cells. It seems likely that the connection between HRS1 and recombination is indirect and involves transcription, because the stability of direct repeats in yeast depends on their level of transcription (Thomas and Rothstein 1989), and mediator mutations may affect global gene expression. A direct role for mediator in the control of genetic stability, however, is not excluded. 
Finally, we note the likely relevance of the activation mechanism in yeast to that in higher cells. Conservation of MED7 from yeast to man is shown here, and similar conservation of MED6 is reported el sewhere (Lee et al. 1997). In all likelihood, an entire Med protein subcomplex, important for activation in yeast, plays a similar role in higher organisms. Homol ogs of SRB7 (Chao et al. 1996) and RGR1 (Y.W. Jiang and R.D. Kornberg) also occur in man, pointing to conservation of the Srb and Gall1 subcomplexes as well.

\section{Materials and methods}

Genetic manipulations

Y east transformations employed lithium acetate (Schiestel and Geitz 1989). Plasmid shuffle techniques were performed as described (Boeke et al. 1987) with the use of 5-fluoro-orotic acid (5-FOA) as a selective agent against U RA 3 plasmids.

Deletions of the entire coding regions of the MED2, MED4, MED 7, and MED 8 genes were performed by a single-step gene disruption technique utilizing PCR amplification of selectable markers (Lorenz et al. 1995). A set of bifunctional PCR primers was constructed with a region of $50 \mathrm{bp}$ at the $5^{\prime}$ end homologous to the flanking sequence of the MED genes. The $3^{\prime}$ end contained 18 bases of homology to the flanking sequence of the marker genes in the pRS303-306 series of vectors (Sikorski and Hieter 1989). PCR knockout products marked MED7 with HIS3, MED 8 with LEU 2, and MED2 and MED 4 with TRP1. These PCR products were transformed into the S. cerevisiae strain CRY3 (Kean et al. 1993) and plated on the appropriate selective media. Yeast genomic DNA was isolated and PCR analysis was performed to confirm that the marker gene had recombined correctly into the target MED gene (see Table 2). The di ploids were sporulated and tetrads $(>15)$ were dissected on YPD agar and scored for nutritional auxotrophies and growth at various temperatures.

Dissection of each tetrad from the MED4/med4::TRP1 (MG101), MED7/med7::HIS3 (MG102), and MED8/med8:: LEU 2(M G103) diploids resulted in two or fewer viable spores. All viable spores were auxotrophs of the appropriate marker, indicating that MED4, MED7, and MED 8 were essential. A PCR product containing $\sim 300$ bp upstream and $\sim 200$ bp downstream of each essential MED gene was cloned into the BamHI-Xhol site of pRS316 (URA3), resulting in pGM 23 (URA3 MED4), pGM 24 (URA 3 MED 7), and pGM 25 (U RA 3 MED8). To confirm that these genes were essential, pGM 23, pGM 24, and pGM 25

Table 2. Yeast strains

\begin{tabular}{|c|c|}
\hline Strain & Genotype \\
\hline CRY 3 & $\begin{array}{l}\text { MATa/ } \alpha \text { ade2-1 can1-100 his3-11,15 leu2-3,112 } \\
\text { trp1-1 ura3-1 }\end{array}$ \\
\hline BJ926 & $\begin{array}{l}\text { MATa/MAT } \alpha \text { trp1/TRP1 Prc1-126/Prc1-126 } \\
\text { pep4-3/pep4/3 prp1-1122/prp1-1122 } \\
\text { can1/can1 }\end{array}$ \\
\hline MG101 & $\begin{array}{l}\text { MATa/ } \alpha \text { ade2-1 can1-100 his3-11,15 leu2-3,112 } \\
\text { trp1-1 ura3-1 med4 } 4:: \text { TRP1/MED3 }\end{array}$ \\
\hline MG102 & $\begin{array}{l}\text { MATa/ } \alpha \text { ade2-1 can1-100 his3-11 15leu2-3,112 } \\
\text { trp1-1 ura3-1 med7 } 1 \text { 1::HIS3/MED7 }\end{array}$ \\
\hline MG103 & $\begin{array}{l}\text { MATa/ } \alpha \text { ade2-1 can1-100 his3-11,15 leu2-3,112 } \\
\text { trp1-1 ura3-1 med8 } 81:: \text { LEU 2/MED8 }\end{array}$ \\
\hline MG104 & $\begin{array}{l}\text { MATa/ } \alpha \text { ade2-1 can1-100 his3-11,15 leu2-3,112 } \\
\text { trp1-1 ura3-1 med2 } 1:: \text { TRP1/MED2 }\end{array}$ \\
\hline
\end{tabular}

were transformed into the strains GM 101, GM 102, and GM 103 and plated on synthetic medium lacking uracil. These diploid transformants were sporulated and the tetrads $(>10)$ were dissected. Viable spores, which were $\mathrm{Ura}^{+}$, and $\operatorname{Trp}^{+}(\mathrm{MED} 4)$, $\mathrm{His}^{+}(\mathrm{MED} 7)$, or Leu ${ }^{+}$(MED8), were streaked on 5-FOA-containing medium. The inability to grow on 5-FOA confirmed that MED4, MED7, and MED8 were essential.

Segregants of each tetrad from the MED2/med2::TRP1 (MG 104) diploid scored 2:2 for tryptophan prototrophy and all tryptophan prototrophs exhibited weak temperature-sensitive, $\mathrm{Gal}^{-}$, and small colony phenotypes, indicating that MED2 deletion strains are conditionally viable. A PCR product containing $\sim 300$ bp upstream and 200 bp downstream of the MED2 gene was cloned into the BamHI-Xhol site of pRS316 (U RA3), yielding pGM 26 (URA3 MED2). The haploid med2::TRP1 strain (M G 105) was transformed with pGM 26 and plated on synthetic medium lacking uracil. This transformed strain complemented all phenotypes of the deletion strain, confirming MED2 as the source of these phenotypes.

\section{Protein purification}

Fractionation of whole cell extract by chromatography on BioRex 70 (Bio-Rad), DEAE-Sephacel (Pharmacia), Bio-Gel HTP hydroxyapatite (Bio-Rad), and M ono Q was as described ( $\mathrm{Li}$ et al. 1996) with the following modifications. Active dry yeast $(2.6 \mathrm{~kg})$ collected before drying (Fleischmann's, Oakland, CA) was suspended in Iysis buffer and the cells were disrupted as described (Kim et al. 1994). After fractionation on hydroxyapatite, the mediator/holopolymerase peak, detected by immunoblotting, was loaded on a Mono Q 10/10 column (Pharmacia). After washing with $40 \mathrm{ml}$ of buffer Q- 0.15 and $40 \mathrm{ml}$ of Q-0.5, the column was developed with a linear gradient $(112 \mathrm{ml})$ of buffer Q-0.5 to Q-1.2. Immunobl otting reveal ed a peak of free mediator eluting around Q-0.6 and a peak of holopolymerase eluting around Q-0.8. The peak of free mediator was pooled and dialyzed against $\mathrm{H}-0.1$ [containing $20 \mathrm{~mm}$ potassium phosphate $(\mathrm{pH}$ 7.6), $10 \%$ glycerol, $0.2 \mathrm{~mm}$ EDTA, $1 \mathrm{~mm}$ DTT, protease inhibitors, and the molarity of potassium acetate indicated after the hyphen] for $4 \mathrm{hr}$. The dialysate was diluted with $\mathrm{H}-0$ to the conductivity of $\mathrm{H}-0.1$ and applied to a TSK-Heparin-5-PW HPLC column ( $3.3 \mathrm{ml}, 75 \times 7.5 \mathrm{~mm}$, Supelco) equilibrated in $\mathrm{H}-0.1$. After washing with two column volumes of $\mathrm{H}-0.1$ and 4 column volumes of $\mathrm{H}-0.25$, the column was developed with a linear gradient $(33 \mathrm{ml})$ of $\mathrm{H}-0.25-\mathrm{H}-0.75$ at a flow rate of 0.5 $\mathrm{ml} / \mathrm{min}$, and fractions of $0.75 \mathrm{ml}$ were collected. The peak of mediator was at $\sim \mathrm{H}-0.4$.

Peak mediator fractions were dial yzed against buffer A-0 [containing $20 \mathrm{~mm}$ HEPES-KOH (pH 7.6), 10\% glycerol, $1 \mathrm{~mm}$ EDTA, $1 \mathrm{~mm}$ DTT, protease inhibitors, and the molarity of potassium acetate indicated after the hyphen], adjusted to a conductivity of A-0.1, and applied to a Mono S 5/5 FPLC column (Pharmacia) equilibrated in A-0.1. After washing with five column volumes of A-0.1 and 5 column volumes of A-0.2, the column was developed with a linear gradient $(12 \mathrm{ml})$ of A-0.2A-1.0 at a flow rate of $0.5 \mathrm{ml} / \mathrm{min}$, and fractions of $0.35 \mathrm{ml}$ were collected. The peak of mediator was at $\sim A-0.5$. To test the homogeneity of the multiprotein complex, a portion $(0.25 \mathrm{ml})$ of the M ono S peak mediator fraction was applied to a Bio-Sil SEC 400 HPLC column (Bio-Rad) equilibrated in A-0.5.

RN A polymerase II holoenzyme was purified from 650 grams of S. cerevisiae strain BJ926 as described in Li et al. (1996).

\section{Protein sequencing}

Peptides were generated from Med2, Med3, Med4, Med7, and Med8 proteins bound to PVDF by tryptic digestion in situ (Erd- 
jument-Bromage et al. 1994; Lui et al. 1996) and were fractionated by reversed-phase HPLC (Elicone et al. 1994) with the use of a 1-mm Reliasil $C_{18}$ column. Selected peak fractions were analyzed by a combination of automated Edman chemical degradation (Tempst et al. 1994) and matrix-assisted laser-desorption ionization time-of-flight mass spectrometry. Peptide sequences were compared with entries in the Saccharomyces $\mathrm{Ge}$ nome Database (SGD, Stanford Genomic Resources, Stanford University) with the use of the $\mathrm{N}$ ational Center for Biotechnology Information (NCBI) BLAST program. Experimental masses of these and additional peptides were compared with the theoretical average isotopic masses of fragments expected to result from tryptic digestion of the identified proteins (with the use of PeptideSearch software; Dr. M atthias M ann, European M olecuIar Biology Laboratory, Heidel berg, Germany).

\section{Antibodies and immunoblot analyses}

Recombinant M ed2, M ed4, Med7, and M ed8 proteins fused to glutathione S-transferase (Table 3) were overproduced in Escherichia coli BL21(DE3) pLysS cells and purified from inclusion bodies as described (Cairns et al. 1994). For each of the GSTMed fusions, $\sim 5 \mathrm{mg}$ of protein was separated by SDS-PAGE and used to immunize rabbits. The antisera used in this study were taken 10 days after the second booster injection (BabCO, Berkeley, CA). Anti-HRS1 antibodies (Santos-Rosa et al. 1996) were a gift from A. Aguilera (Universidad de Sevilla, Spain). Anti-RPB3 antibodies were a gift from R. Burgess and N. Thompson (M cA rdle Laboratory for Cancer Research, Madison, WI).
Immunoprecipitation

Anti-M ed2 and anti-M ed4 antibodies were coupled to protein A-Sepharose beads and were used to immunoprecipitate a purified holopolymerase as described ( $\mathrm{Li}$ et al. 1995), with the following modifications. Prior to incubation with the holopolymerase fraction, $50 \mu \mathrm{l}$ of the anti-M ed6 beads were washed with $100 \mu \mathrm{l}$ of $50 \mathrm{~mm}$ glycine (pH 2.3), $150 \mathrm{~mm} \mathrm{NaCl}$, followed by several washes with $100 \mu$ l of IP-200 wash buffer (20 mM HEPES at $\mathrm{pH} 7.6,10 \%$ glycerol, $12.5 \mathrm{~mm} \mathrm{M} \mathrm{gCl}, 0.1 \mathrm{~mm}$ EDTA, $0.2 \%$ N P-40, $0.1 \mathrm{~mm}$ DTT, $200 \mathrm{~mm}$ potassium acetate). A M ono Q fraction of holopolymerase $(10 \mu \mathrm{l})$ was diluted with $40 \mu \mathrm{l}$ of buffer Q-0.5 (no dithiothreitol or protease inhibitors), centrifuged for $5 \mathrm{~min}$ at 13,000 rpm, and incubated with the beads for $4 \mathrm{hr}$ at $4^{\circ} \mathrm{C}$. The beads were then washed three times with 200 $\mu \mathrm{l}$ of buffer IP-200 and el uted twice with $17.5 \mu \mathrm{l}$ of $5 \mathrm{M}$ urea (10 $\mathrm{min}$ at room temperature). The el uates combined with $20 \mu \mathrm{l}$ of $2 \times$ SDS gel-loading buffer were loaded on gels for immunoblotting.

Transcription and CTD phosphorylation assays

Transcription and CTD phosphorylation assays were performed as described (Kim et al. 1994), with the following modifications. Pure TFIIF (Henry et al. 1992) was added to all transcription reactions, and TFIIH was purified as described by Svejstrup et al . (1994). All transcription reactions were performed at a final potassium acetate concentration of $180 \mathrm{~mm}$.

Table 3. Plasmids

\begin{tabular}{|c|c|}
\hline Plasmid & Description \\
\hline pGM 23 & $\begin{array}{l}\text { pRS316 with the BamHI-Xhol fragment removed and a PCR product, using the oligonucleotides } \\
\text { 5'-dCGCGGGATCCAGAATGCGAATGCACAG-3' and 5'-dCGCGCTCGAGTTTTCCAGTTCCTGTGG-3' } \\
\text { containing the full MED4 coding sequence inserted. }\end{array}$ \\
\hline pGM 24 & $\begin{array}{l}\text { pRS316 with the BamHI-Xhol fragment removed and a PCR product (PCR with oligonucleotides } \\
\text { 5'-dCGCGGGATCCCATCAACATCCATCCTG-3' and 5'-dCGCGCTCGAGAATCTCGGAAATACGTC-3') } \\
\text { containing the full MED7 coding sequence inserted. }\end{array}$ \\
\hline pGM 25 & $\begin{array}{l}\text { pRS316 with the BamHI-Xhol fragment removed and a PCR product (PCR with the oligonucleotides } \\
\text { 5'-dCGCGGGATCCAGTTATTACTTGGGTCC-3' and 5'-dCGCGCTCGAGAACCTACTAAGGTTTCC-3') } \\
\text { containing the full MED8 coding sequence inserted. }\end{array}$ \\
\hline pGM 26 & $\begin{array}{l}\text { pRS316 with the Xbal-Xhol fragment removed and a PCR product (PCR with oligonucleotides } \\
\text { 5'-dGCGCTCTAGAGCAAGGCCAGAGCTTGTCAAT-3' and } \\
\text { 5'-dCGCGCTCGAGGCATGCATCTCTCACATGACG-3') containing the full MED2 coding sequence } \\
\text { inserted. }\end{array}$ \\
\hline pGM 27 & $\begin{array}{l}\text { pGEX-3X with the BamHI-EcoRI fragament removed and a PCR product (PCR with oligonucleotides } \\
\text { 5'-dGCGCGCGGATCCCCATGTCTGTCCAAGATACTAAAG-3' and } \\
\text { 5'-dCCGGCCGAATTCTTAGAAGTCGTCCGGATCAAACA-3') containing the full MED4 coding sequence } \\
\text { inserted. }\end{array}$ \\
\hline pGM 28 & $\begin{array}{l}\text { pGEX-3X with the BamHI-EcoRI fragment removed and a PCR product (PCR with oligonucleotides } \\
\text { 5'-dGCGCGCGGATCCCCATGTCCAATGATCCTGGTAAT-3' and } \\
\text { 5'-dCCGGCCGAATTCTTATTGGGACGACGATGGAGGAG-3') containing the full MED7 coding sequence } \\
\text { inserted. }\end{array}$ \\
\hline pGM 29 & $\begin{array}{l}\text { pGEX-3X with the BamHI-EcoRI fragment removed and a PCR product (PCR with oligonucleotides } \\
\text { 5'-dGCGCGCGGATCCCCATGTCACAATCTACTGCATCA-3' and } \\
\text { 5'-dCCGGCCGAATTCTTAATTACTAGATGATGTTGAAGTA-3') containing the full MED } 8 \text { coding } \\
\text { sequence inserted. }\end{array}$ \\
\hline pGM 30 & $\begin{array}{l}\text { pGEX-3X with the BamHI-ECoRI fragment removed and a PCR product (PCR with oligonucleotides } \\
\text { 5'-dGCGCGCGGATCCCCATGGTAGTACAAAATAGCCC-3' and } \\
\text { 5'-dCCGGCCGAATTCTTATCGTTGAACATTACATCCGA-3' containing the first } 25 \mathrm{kD} \text { of the MED2 } \\
\text { coding sequence inserted. }\end{array}$ \\
\hline
\end{tabular}




\section{Mediator-CTD interaction}

To construct a GST-CTD expression construct the carboxyterminal domain of Rpb1 was amplified by PCR, by use of the primers 5'-GCGCGCGGATCCCCAATGACGCTATGGCTGGAGG-3' and 5'-CCGGCCGAATTCTTATCATCTGGAATTTTCATTTTCAT-3'. The PCR product was then cleaved with EcoRI and BamHI, and inserted into pGEX-3X (Pharmacia). Pure GST-CTD and GST $(30 \mu \mathrm{g})$ were bound to $25 \mu \mathrm{l}$ of Glutathione Sepharose 4B (Pharmacia) following the manufacturer's instructions. The GST-CTD and GST resins were incubated with $1 \mu \mathrm{g}$ of pure mediator diluted in $100 \mu \mathrm{l}$ of buffer T-0.3 [buffer A containing $20 \mathrm{~mm}$ Tris-Acetate (pH 7.8), 10\% glycerol, $0.2 \mathrm{~mm}$ EDTA, $0.01 \% \mathrm{NP}-40,1 \mathrm{~mm}$ DTT, and the molarity of potassium acetate indicated after the hyphen] for $2 \mathrm{hr}$ at $4^{\circ} \mathrm{C}$ with gentle agitation, followed by three washes with buffer $\mathrm{T}$ 0.2 plus $0.1 \%$ N P-40. The resins were eluted first with $10 \mathrm{~mm}$ reduced glutathione, $50 \mathrm{~mm}$ Tris-acetate $(\mathrm{pH} 7.8)$ and then by boiling in SDS-PAGE buffer. The load, supernatant, washes, and elutes were analyzed by SDS-PAGE and immunoblotting.

\section{Identification of human MED7 homolog}

All of the newly discovered MED genes described here were compared with the human EST database by use of the NCBI BLAST program. Two partially overlapping sequences (GenBank clones $6652015^{\prime}$ and $1391905^{\prime}$ ) were found with significant homology to yeast MED7 (yMED7). A BgllI-HindlII fragment from clone $1391905^{\prime}$ was excised and ligated into the BgllI-HindlII sites in clone $6652015^{\prime}$ to make a construct containing a full-length sequence for hMED 7. The construct was sequenced and a start codon assigned based on homology with the yeast protein.

\section{Acknowledgments}

We thank $G$. Jensen for purified transcription proteins and $B$. Cairns for much help in the analysis of the $\Delta$ med2 phenotype. L.C.M . was a recipient of a Cancer Research Fund of the Damon Runyon-Walter Winchell Foundation Fellowship, DRG-1361. C.M.G. was a recipient of a Swedish Cancer Society postdoctoral fellowship. This research was supported by $\mathrm{N}$ ational Institutes of Health grant GM 36659 to R.D.K., by N ational Science Foundation grant DBI-940123 to P.T., and by $\mathrm{N}$ ational Cancer Institutes core grant 5 P30 CA 08748 to the Sloan-Kettering Sequencing Laboratory.

The publication costs of this article were defrayed in part by payment of page charges. This article must therefore be hereby marked "advertisement" in accordance with 18 USC section 1734 solely to indicate this fact.

\section{References}

Boeke, J., J. Truehart, B. N atsoulis, and G.R. Fink. 1987. 5-Fluoroorotic acid as a sel ective agent in yeast molecular genetics. Methods Enzymol. 154: 164-175.

Bröhl, S., T. Lisowsky, G. Riemen, and G. Michaelis. 1994. A new nuclear suppressor system for a mitochondrial RNA polymerase mutant identifies an unusual zinc-finger protein and a polyglutamine domain protein in Saccharomyces cerevisiae. Yeast 10: 719-731.

Burley, S.K. and R.G. Roeder. 1996. Biochemistry and structural biology of transcription factor IID (TFIID). Annu. Rev. Biochem. 65: 769-799.

Cairns, B.R., Y.J. Kim, M.H. Sayre, B.C. Laurent, and R.D. Kornberg. 1994. A multisubunit complex containing the SWI1-
ADR6, SWI2-SNF2, SWI3, SNF5, and SNF6 gene products isolated from yeast. Proc. Natl. Acad. Sci. 91: 1950-1954.

Chao, D.M., E.L. Gadbois, P.J. Murray, S.F. Anderson, M.S. Sonu, J.D. Parvin, and R.A. Young. 1996. A mammalian SRB protein associated with an RNA polymerase II holoenzyme. Nature 380: 82-85.

Démolis, N., L. Mallet, F. Bussereau, and M. Jacquet. 1993. RIM 2, MSI 1 and PGII are located within an $8 \mathrm{~kb}$ segment of Saccharomyces cerevisiae chromosome II, which also contains the putative ribosomal gene $L 21$ and a new putative essential gene with a leucine zipper motif. Yeast 9: 645-659.

Elicone, C., M. Lui, S. Geromanos, H. Erdjument-Bromage, and P. Tempst. 1994. Microbore reversed-phase high-performance liquid chromatographic purification of peptides for combined chemical sequencing-laser-desorption mass spectrometric analysis. J. Chromatogr. 676: 121-137.

Erdjument-Bromage, H., M. Lui, D.M. Sabatini, S.H. Snyder, and P. Tempst. 1994. High-sensitivity sequencing of large proteins: Partial structure of the rapamycin-FKBP12 target. Protein Sci. 3: 2435-2446.

Fan, H.-Y., K.K. Cheng, and H.L. Klein. 1996. Mutations in the RNA polymerase II transcription machinery suppress the hyper recombination mutant hprls of Saccharomyces cerevisiae. Genetics 142: 749-759.

Flanagan, P.M., R.J. Kelleher III, M.H. Sayre, H. Tschochner, and R.D. Kornberg. 1991. A mediator required for activation of RN A polymerase II transcription in-vitro. Nature 350: 436438.

Gustafsson, C.M., L.C. Myers, Y. Li, M.J. Redd, M. Lui, H. Erdjument-Bromage, P. Tempst, and R.D. Kornberg. 1997. Identification of Rox3 as a component of mediator and RNA polymerase II holoenzyme. J. Biol. Chem. 272: 48-50.

Hengartner, C.J., C.M. Thompson, J. Zhang, D.M. Chao, S.M. Liao, A.J. Koleske, S. Okamura, and R.A. Young. 1995. Association of an activator with an RNA polymerase II holoenzyme. Genes \& Dev. 9: 897-910.

Henry, N.L., M.H. Sayre, and R.D. Kornberg. 1992. Purification and characterization of yeast RNA polymerase II general initiation factor g. J. Biol. Chem.267: 23388-23392.

Jiang, Y.W. and D.J. Stillman. 1995. Regulation of HIS4 expression by the Saccharomyces cerevisiae SIN 4 transcriptional regulator. Genetics 140: 103-114.

Jiang, Y.W., P.R. Dohrmann, and D.J. Stillman. 1995. Genetic and physical interactions between yeast RGRI and SIN 4 in chromatin organization and transcriptional regulation. Genetics 140: 47-54.

Kean, L.S., R.S. Fuller, and J.W. N ichols. 1993. Retrograde lipid traffic in yeast: Identification of two distinct pathways for internalization of fluorescent-labeled phosphatidylcholine from the plasma membrane. J. Cell. Biol. 123: 1403-1419.

Kelleher, R.J., III, P.M. Flanagan, and R.D. Kornberg. 1990. A novel mediator between activator proteins and the RNA polymerase II transcription apparatus. Cell 61: 1209-1216.

Kim, Y.J., S. Bjorklund, Y. Li, M.H. Sayre, and R.D. Kornberg. 1994. A multiprotein mediator of transcriptional activation and its interaction with the C-terminal repeat domain of RNA polymerase II. Cell 77: 599-608.

Koleske, A.J. and R.A. Young. 1994. An RNA polymerase II holoenzyme responsive to activators. Nature 368: 466-469.

Lee, Y.C., S. Min, B.S. Gim, and Y.J. Kim. 1997. A transcriptional mediator protein that is required for activation of many RNA polymerase II promoters is conserved from yeast to humans. Mol. Cell. Biol. 17: 4622-4632.

Li, Y. and R.D. Kornberg 1994. Interplay of positive and negative effectors in function of the $\mathrm{C}$-terminal repeat domain of RNA polymerase II. Proc. Natl. Acad. Sci. 91: 2362-2366. 
Li, Y., S. Bjorklund, Y.W. Jiang, Y.J. Kim, W.S. Lane, D.J. Stillman, and R.D. Kornberg. 1995. Yeast global transcriptional regulators Sin4 and Rgrl are components of mediator complex-RN A polymerase II holoenzyme. Proc. Natl. Acad. Sci. 92: 10864-10868.

Li, Y., S. Bjorklund, Y.J. Kim, and R.D. Kornberg. 1996. Yeast RNA polymerase II holoenzyme. Methods Enzymol. 273: 172-175.

Liao, S.M., I.C.A. Taylor, R.E. Kingston, and R.A. Young. 1991. RN A polymerase II carboxy-terminal domain contributes to the response to multiple acidic activators in vitro. Genes \& Dev. 5: 2431-2440.

Lorenz, M.C., R.S. M uir, E. Lim, L. M cElver, S.C. Weber, and J. Heitman. 1995. Gene disruption with PCR products in Saccharomyces cerevisiae. Gene 158: 113-117.

Lui, M., P. Tempst, and H. Erdjument-Bromage. 1996. M ethodical analysis of protein-nitrocellulose interactions to design a refined digestion protocol. Anal. Biochem. 241: 156-166.

Moqtaderi, Z., Y. Bai, D. Poon, P.A. Weil, and K. Struhl. 1996. TBP-associated factors are not generally required for transcriptional activation in yeast. Nature 383: 188-191.

Pearson, W.R. and D.J. Lipman. 1988. Improved tools for biological sequence comparison. Proc. Natl. Acad. Sci. 85: 2444-2448.

Piruat, J.I. and A. Aguilera. 1996. Mutations in the yeast SRB2 general transcription factor suppress hprl-induced recombination and show defects in DN A repair. Genetics 143: 15331542.

Piruat, J.I., S. Chavez, and A. Aguilera. 1997. The yeast HRS1 gene is involved in positive and negative regulation of transcription and shows genetic characteristics similar to Sin4 and GAI11. Genetics (in press).

Pugh, B.F. and R. Tjian. 1990. Mechanism of transcriptional activation by Sp1: Evidence for coactivators. Cell 61: 11871198.

Santos-Rosa, H. and A. Aguilera. 1995. Isolation and genetic analysis of extragenic suppressors of the hyper-deletion phenotype of the Saccharomyces cerevisiae hprls mutation. Genetics 139: 57-66.

Santos-Rosa, H., B. Clever, W.D. Heyer, and A. Aguilera. 1996. The yeast HRS1 gene encodes a polygl utamine-rich nuclear protein required for spontaneous and hprl-induced del etions between direct repeats. Genetics 142: 705-716.

Scafe, C., D. Chao, J. Lopes, J.P. Hirsch, S. Henry, and R.A. Young. 1990. RNA polymerase II C-terminal repeat influences response to transcriptonal enhancer signals. Nature 347: 491-494.

Schiestl, R.H. and R.D. Gietz. 1989. High efficiency transformation of intact yeast cells using single stranded nucleic acids as a carrier. Curr. Genet. 16: 339-346.

Sikorski, R.S. and P. Hieter. 1989. A system of shuttle vectors and yeast host strains designed for efficient manipulation of DN A in Saccharomyces cerevisiae. Genetics 122: 19-28.

Svejstrup, J.Q., W.J. Feaver, J. Lapointe, and R.D. Kornberg. 1994. RN A polymerase transcription factor IIH holoenzyme from yeast. J. Biol. Chem. 269: 28044-28048.

Svejstrup, J.Q., Y. Li, J. Fell lows, A. G natt, S. Bjorklund, and R.D. Kornberg. 1997. Evidence for a mediator cycle at the initiation of transcription. Proc. Natl. Acad. Sci. 94: 6075-6078.

Tempst, P., S. Geromanos, C. Elicone, and H. Erdjument-Bromage. 1994. Improvements in microsequencer performance for low picomole sequence analysis. Methods Comp. Meth. Enzymol. 6: 248-261.

Thomas, B.J. and R. Rothstein. 1989. Elevated recombination rates in transcriptionally active DNA. Cell 56: 619-630.
Thompson, C.M., A.J. Koleske, D.M. Chao, and R.A. Young 1993. A multisubunit complex associated with the RNA polymerase II CTD and TATA-binding protein in yeast. Cell 73: 1361-1375.

Thompson, C.M. and R.A. Young. 1995. General requirement for RNA polymerase II holoenzymes in vivo. Proc. Natl. Acad. Sci. 92: 4587-4590.

Walker, S.S., J.C. Reese, L.M. A pone, and M. Green. 1996. Transcription activation in cells lacking TAF-lls. Nature 383: 185-188. 


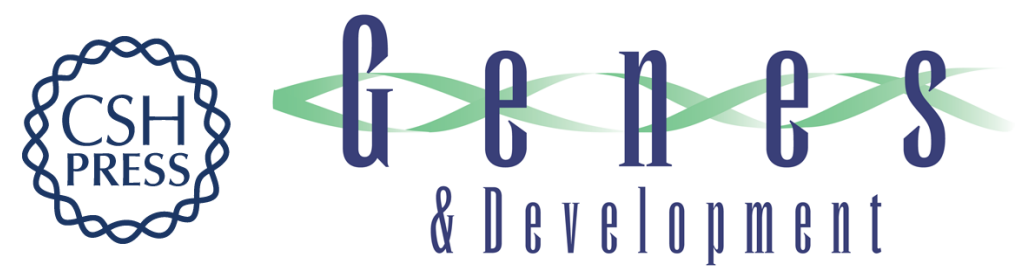

\title{
The Med proteins of yeast and their function through the RNA polymerase II carboxy-terminal domain
}

\author{
Lawrence C. Myers, Claes M. Gustafsson, David A. Bushnell, et al.
}

Genes Dev. 1998, 12:

Access the most recent version at doi:10.1101/gad.12.1.45

$\begin{array}{ll}\text { References } & \text { This article cites } 41 \text { articles, } 20 \text { of which can be accessed free at: } \\ \text { http://genesdev.cshlp.org/content/12/1/45.full.html\#ref-list-1 }\end{array}$

License

Email Alerting Receive free email alerts when new articles cite this article - sign up in the box at the top Service right corner of the article or click here.

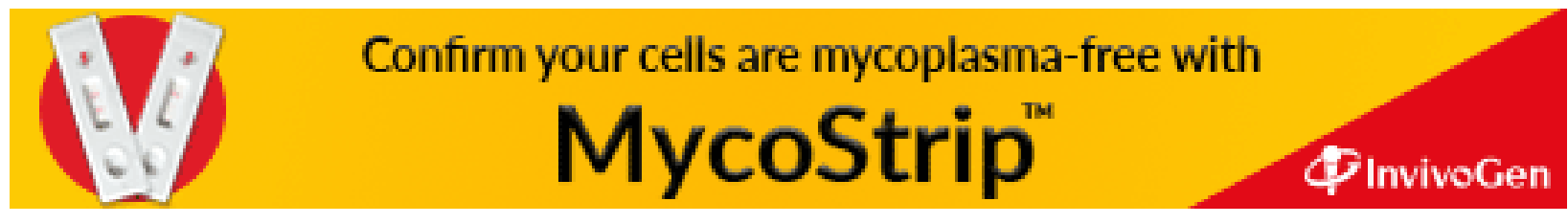

